\title{
Anomalous origin and retroaortic course of the left circumflex artery: a mystery of a grown-up patient with congenital heart disease solved after 15 years
}

\author{
Olga Możeńska1', Patryk Buller², Maria Różańska', Robert J. Gil³, Jacek Bil \\ 1 Department of Internal Medicine, Hypertension and Vascular Diseases, Warsaw Medical University, Warsaw, Poland \\ 2 Department of Cardiology, Regional Hospital in Plock, Płock, Poland \\ 3 Department of Invasive Cardiology, Center of Postgraduate Medical Education, Warsaw, Poland
}

Correspondence to: Jacek Bil, MD, PhD, FESC, Department of Invasive Cardiology, Center of Postgraduate Medical Education, ul. Wołoska 137, 02-507 Warszawa, Poland, phone: +48225081100 , email: biljacek@gmail.com Received: January 19, 2021. Revision accepted: March 2, 2021. Published online: March 12, 2021. Kardiol Pol. 2021; 79 (4): 475-476 doi:10.33963/KP.15872 Copyright by the Author(s), 2021
In recent years, the number of grown-up patients with congenital heart disease (GUCH) has been steadily increasing due to the remarkable improvement in the survival of individuals with this disease. ${ }^{1}$

In 1999, a 23-year-old male patient with patent ductus arteriosus (recognized during qualification for a surgery) and severe aortic regurgitation (diagnosed in early childhood and followed up) underwent cardiac surgery. During the procedure, a sudden aortic annulus rupture resulted in extension of cardiopulmonary bypass duration and the need to replace the aortic valve (with a tilting-disc Medtronic Hall prosthesis; Medtronic; Fridley, Minnesota, United States). Intraoperative echocardiography showed massive inferolateral myocardial infarction. Left circumflex artery (LCx) ligation was suspected, but no coronary imaging was performed. After 3 months, the patient was discharged with heart failure and ejection fraction (EF) of $20 \%$. In the following years, he required numerous hospitalizations, including an implantation of a cardiac resynchronization therapy defibrillator (CRT-D). He turned out to be a CRT super-responder and showed an improvement in the EF (increase to $40 \%$ ) along with left ventricular diastolic diameter of $60 \mathrm{~mm}$, left atrial diameter of $46 \mathrm{~mm}$, moderate functional mitral regurgitation (MR) with effective regurgitant orifice of $0.19 \mathrm{~cm}^{2}$, MR volume of $29 \mathrm{ml}$, and mild pulmonary hypertension. Unfortunately, later, his clinical status slowly, but continuously, deteriorated. The EF lowered to $20 \%$, left ventricular diastolic diameter extended to $76 \mathrm{~mm}$, and MR became severe (effective regurgitant orifice, $0.24 \mathrm{~cm}^{2}$; MR volume, $41 \mathrm{ml}$ ). The patient was on bisoprolol, digoxin, amiodarone, ramipril, torasemide, eplerenone, allopurinol, and acenocoumarol. Therefore, 15 years after the index surgery, the Heart Team discussed possible options. Cardiac computed tomography was performed in preprocedural planning. Surprisingly, it revealed a fully patent LCx. It originated from the right aortic sinus and had a retroaortic course, passing between the aorta and left atrium (FIGURE 1A-1D). This brought new insight into what happened in 1999. The LCx was not ligated, but the lack of knowledge about its anomalous origin resulted in improperly administered cardioplegia, which led to further unfavorable consequences. Finally, the patient was referred for percutaneous treatment of MR with MitraClip. Unfortunately, he did not manage to undergo the procedure due to sudden cardiac death.

Coronary anomalies in patients with congenital heart disease are rare. ${ }^{2}$ Based on the currently available data, the European Society of Cardiology (ESC) practice guidelines recommend routine assessment of the coronary arteries in valvular heart disease only to diagnose coronary artery disease. ${ }^{1}$ The same recommendations appeared in the latest guidelines released during the ESC Congress in $2020 .^{3} \mathrm{Ac}-$ cording to these guidelines, cardiac computed tomography in patent ductus arteriosus is only indicated when additional quantification of left ventricular volumes or evaluation of pulmonary artery anatomy is required. ${ }^{1}$ So, 

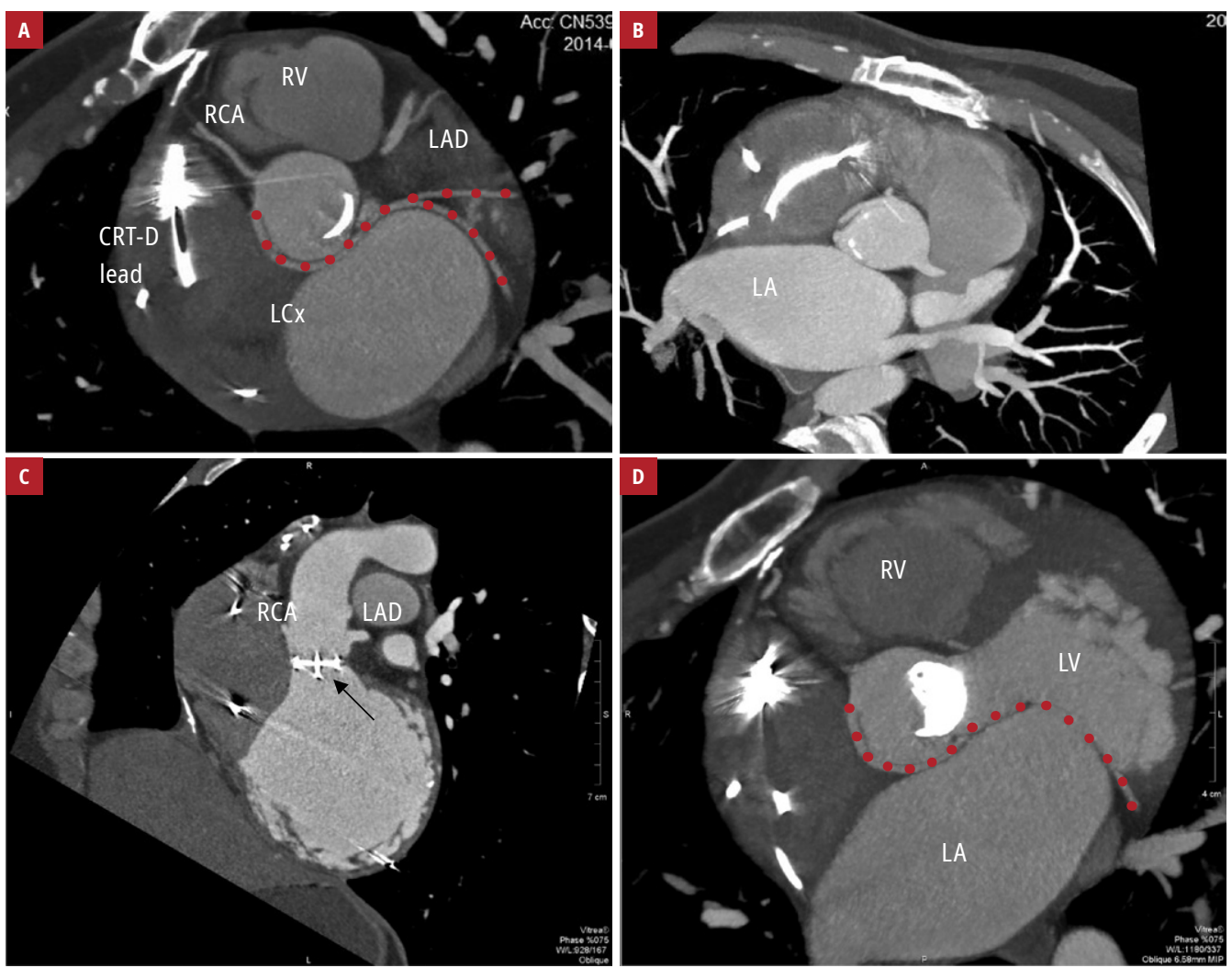

FIGURE 1 Cardiac computed tomography imaging; A - anomalous course of the left circumflex artery (LCX) originating from the opposite (ie, right) sinus of Valsalva (marked with red dots); B - separate take-off of the left arterior descending artery (LAD); C - the tilting-disc aortic valve prosthesis (Medtronic-Hall) indicated by the arrow; D - another view of the anomalous course of the LCX from the right sinus of Valsalva (marked with red dots)

Abbreviations: CRT-D, cardiac resynchronization therapy defibrillator; LA, left atrium; LV, left ventricle; RCA, right coronary artery; $\mathrm{RV}$, right ventricle

even though back in 1999 neither of the cited ESC guidelines were available for the surgeons who operated on our patient, today, if the guidelines would be followed step by step, one can easily imagine a repetition of such clinical scenario.

GUCH patients referred for cardiac surgery often do not meet the eligibility criteria for preoperative imaging of coronary arteries. However, they still fulfil the requirement for individualization of medical therapy, since behind every GUCH patient there is an individual clinical history and a unique coexistence of congenital cardiac defects.

\section{ARTICLE INFORMATION}

NOTE The case was presented at the Heart Failure Congress on April 29 to May 2, 2017 in Paris, France and at the TCT Connect on October 14 to 18, 2020 (TCT-693).

\section{CONFLICT OF INTEREST None declared.}

OPEN ACCESS This is an Open Access article distributed under the terms of the Creative Commons Attribution-NonCommercial-NoDerivatives $4.0 \mathrm{In}$ ternational License (CC BY-NC-ND 4.0), allowing third parties to download articles and share them with others, provided the original work is properly cited, not changed in any way, distributed under the same license, and used for noncommercial purposes only. For commercial use, please contact the journal office at kardiologiapolska@ptkardio.pl.

HOW TO CITE Możeńska 0, Buller P, Różańska M, et al. Anomalous origin and retroaortic course of the left circumflex artery: a mystery of a grown-up patient with congenital heart disease solved after 15 years. Kardiol Pol. 2021; 79: 475-476. doi:10.33963/KP.15872

\section{REFERENCES}

1 Baumgartner H, Falk V, Bax JJ, et al. 2017 ESC/EACTS Guidelines for the management of valvular heart disease. Eur Heart J. 2017; 38: 2739-2791.

2 Opolski MP, Pregowski J, Kruk M, et al. Prevalence and characteristics of coronary anomalies originating from the opposite sinus of Valsalva in 8,522 patients referred for coronary computed tomography angiography. Am J Cardiol. 2013; 111 : 1361-1367.

3 Baumgartner H, De Backer J, Babu-Narayan SV, et al. 2020 ESC Guidelines for the management of adult congenital heart disease. Eur Heart J. 2021; 42: 563-645. 